\title{
Relation of Ethnicity and Menopausal Symptoms in Nepal
}

\author{
Swaraj Rajbhandari, A Amatya, Kanti Giri
}

\section{ABSTRACT}

A cross-sectional study was conducted among women of different ethnic groups aged 40 to 60 years and health workers in different parts of Nepal using focus group discussions (FGDs), key informant interviews (KIIs) and clinical examinations to determine the symptoms and complains related to menopause.

The mean age at menarche was 15 years and the mean age of menopause was 47 . The highest menarche and menopause (50 years) was found to be among the Gurung women. Mean age of menopause was found to be higher among currently older women (52 years among 60+ women vs 41 years among < 45 years women) and unmarried women. Tharu perimenopausal women and Sarki, Gurung and Tharu postmenopausal women were found to have relatively more regular menstrual cycles. However, Tharu perimenopausal women were found to have excess bleedings during the menstrual cycle.

Most of the women had heard about menopause but did not have detailed knowledge on it. Loss of sexual interest (95.3\%), decreased visual activity (58\%), joint pain (31.3\%) and body pain $(31.3 \%)$ were the most commonly reported menopausal symptoms. Mean body mass index (BMI) was highest among the Gurung women (both perimenopausal and postmenopausal). Pap smear was normal in all 138 women but around $50 \%$ had some cervical and vaginal-related problems. One-third of Tharu postmenopausal women had atropic labia and onethird of Tamang women had leukoderma.

Since, very little knowledge is known about the postmenopausal symptoms and problems in Nepal, this study can serve as the basis for further researches in this area with an increased sample size.

Keywords: Ethnic groups, Menarche, Perimenopause, Postmenopause, Menopausal symptoms.

How to cite this article: Rajbhandari S, Amatya A, Giri K. Relation of Ethnicity and Menopausal Symptoms in Nepal. J South Asian Feder Menopause Soc 2013;1(2):50-55.

\section{Source of support: Nil}

Conflict of interest: None declared

\section{INTRODUCTION}

Although menopause is a natural event in the life cycle perspective, Menopausal age and symptoms have been a neglected issue in Nepal although the awareness of the situation does prevail. About $17.6 \%$ of the women are above the age of 40 years (NDHS 2011) and lack of paucity on studies of the menopausal age in different ethnic groups is seen. Adequate work has not been carried out yet and there is yet much to be done to address the morbidities caused by this.

\section{STUDY OBJECTIVES}

To determine the average age of menopause of Nepalese women and to find out the symptoms and the complaints of Nepalese women among different ethnic groups.

\section{METHODOLOGY}

Qualitative and quantitative study was conducted in five VDCs (Mahankal, Jharuwarashi, Chapagaun, Pathihani and Pathihari), two municipalities (Sanothimi and Hetauda) and one submetropolitan city (Pokhara) and four districts (Kathmandu, Kaski, Makwanpur and Chitwan). The study involved 40 to 60 years women from ethnic groups of Bahun, Chhetri, Gurung (Tamu), Newar, Sarki, Tamang and Tharus. The total number of participants was 150 in focus group discussion (FGD) and six in key informant interview (KII). KIIs was conducted in Teaching Hospital (Kathmandu), Gandaki Hospital (Kaski) and Bharatpur Hospital (Chitwan) with midwives and staff nurse. Clinical examination was done in 138 women. The tools for data collection were FGD guidelines, KII guidelines and clinical examination questionnaire.

\section{Limitations}

The study population did not include various regions and only selective ethnic groups were involved. The number of participants in each group was not even and most of the participants were illiterate so there could be recall biases.

\section{Findings}

\section{Age Group}

From Table 1, it is seen that majority of the women in the study population were of the age group 45 to 49 and 50 to 54 years with Sarki (46.7) and Newar (60) being the highest in each age group respectively. Tamang had 36.7 representation in the each aforesaid age group.

\section{Marital Status}

As seen in Graph 1, 46.7\% of the Newar women, $26.7 \%$ of the Sarki women and $20 \%$ of Tamang are widows. Similarly, $91.3 \%$ Tharu, $84.6 \%$ mixed ethnic group and $80 \%$ Tamang women were married. The proportion of separated women was higher among Brahmin and Chhetris. The proportion of unmarried women in Newar, Sarki and Gurungs were $6.7,6.7$ and $3.3 \%$ respectively.

\section{Age of Menarche}

Mean age of menarche was 15 years among all the ethnic groups with the highest being 16 years and the lowest being 
Relation of Ethnicity and Menopausal Symptoms in Nepal

\begin{tabular}{lllllll}
\hline \multicolumn{7}{c}{ Table 1: Age group of the respondents } \\
\cline { 2 - 6 } Caste/ethnicity & \multicolumn{5}{c}{ Age group of the women by ethnicity } & Total \\
\cline { 2 - 6 } & Less than 45 years & 45-49 years & $50-54$ years & $55-59$ years & $60+$ years & 100 \\
\hline Gurung & 3.3 & 20 & 26.7 & 20 & 30 & 100 \\
Sarki & 0 & 46.7 & 33.3 & 13.3 & 6.7 & 100 \\
Newar & 0 & 6.7 & 60 & 26.7 & 6.7 & 100 \\
Bahun/Chhetri & 8.3 & 41.7 & 25 & 16.7 & 8.3 & 100 \\
Tharu & 4.3 & 34.8 & 17.4 & 21.7 & 21.7 & 100 \\
Tamang & 3.3 & 36.7 & 36.7 & 20 & 3.3 & 1.7 \\
Mixed group & 23.1 & 23.1 & 23.1 & 23.1 & 7.7 & 100 \\
\hline
\end{tabular}

Table 2: Age at menarche

\begin{tabular}{llll}
\hline Caste/ethnicity & Mean age & SD & $N$ \\
\hline Gurung & 16 & 2 & 30 \\
Sarki & 15 & 2 & 15 \\
Newar & 15 & 2 & 15 \\
Bahun/Chhetri & 16 & 2 & 12 \\
Tharu & 13 & 1 & 23 \\
Tamang & 16 & 2 & 30 \\
Mixed group & 15 & 1 & 13 \\
Group total & 15 & 2 & 138 \\
\hline
\end{tabular}

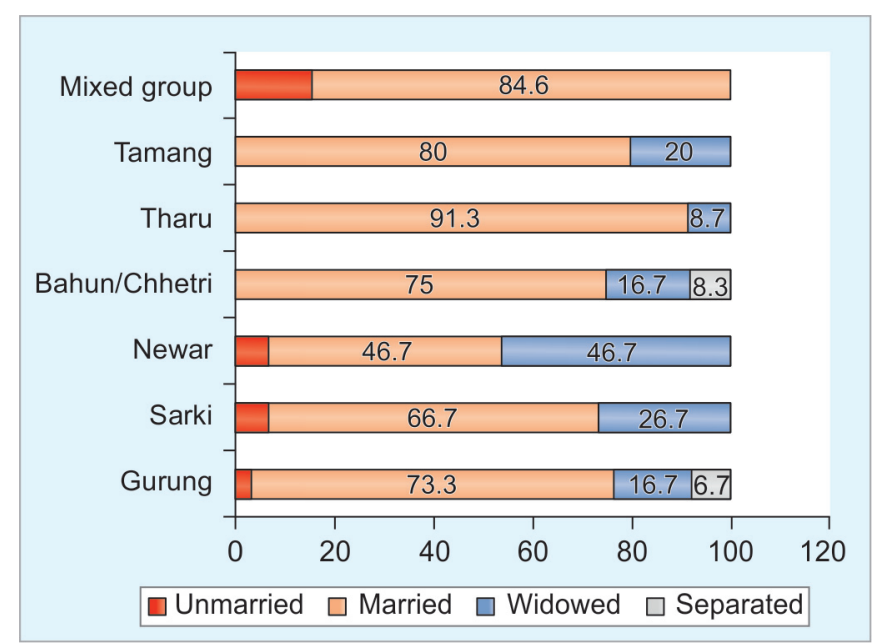

Graph 1: Marital status of the respondents by ethnic groups $(n=138)$

13 years. Gurung, Tamang and Bahun/Chhetri had the highest menarche age and Tharu had the lowest (Table 2).

\section{Menopausal Status}

Majority of the women's status was postmenopausal. The proportion of postmenopausal women ranged from $60 \%$ among Sarki women to $100 \%$ in Newar women. More than $90 \%$ postmenopausal women were from the ethnic group in the study population (Table 3).

\section{Age of Menopause by Ethnicity}

The mean age of menopause was 47 years. Gurung women had the highest menopause age (50 years) and Bahun/ Chhetri had the lowest age (44 years) (Table 4).
Table 3: Menopausal status by ethnicity

\begin{tabular}{llll}
\hline \multicolumn{3}{c}{ Menopausal status } \\
\hline Caste/ethnicity & Perimenopause & Postmenopause & Total \\
\hline Gurung & 23.3 & 76.7 & 100 \\
Sarki & 40 & 60 & 100 \\
Newar & 0 & 100 & 100 \\
Bahun/Chhetri & 8.3 & 91.7 & 100 \\
Tharu & 4.3 & 95.7 & 100 \\
Tamang & 3.3 & 96.7 & 100 \\
Mixed group & 23.1 & 76.9 & 100 \\
\hline
\end{tabular}

Table 4: Age of menopause by ethnic groups

\begin{tabular}{lcc}
\hline Caste/ethnicity & $\begin{array}{l}\text { Age of the women } \\
\text { by ethnicity (years) }\end{array}$ \\
\hline & Mean age $\pm S D$ & $N$ \\
\cline { 2 - 3 } Gurung & $50 \pm 4$ & 30 \\
Sarki & $47 \pm 3$ & 15 \\
Newar & $48 \pm 7$ & 15 \\
Bahun/Chhetri & $44 \pm 8$ & 12 \\
Tharu & $47 \pm 5$ & 23 \\
Tamang & $46 \pm 4$ & 30 \\
Mixed group & $47 \pm 4$ & 13 \\
Group total & $47 \pm 5$ & 138 \\
\hline
\end{tabular}

Table 5: Age of menopause by current age of women

\begin{tabular}{lll}
\hline Age & $\begin{array}{l}\text { Age of menopause by } \\
\text { age of women (years) }\end{array}$ \\
\hline & Mean age $\pm S D$ & $N$ \\
\cline { 2 - 3 } Less than 45 years & $41 \pm 7$ & 7 \\
45-49 years & $43 \pm 5$ & 41 \\
$50-54$ years & $47 \pm 5$ & 43 \\
55-59 years & $49 \pm 4$ & 28 \\
60+ years & $52 \pm 3$ & 19 \\
Group total & $47 \pm 5$ & 138 \\
\hline
\end{tabular}

Table 6: Age of menopause by marital status

\begin{tabular}{lll}
\hline Caste/ethnicity & Mean age $\pm S D$ & $N$ \\
\hline Unmarried & $49 \pm 1$ & 5 \\
Married & $47 \pm 6$ & 104 \\
Widowed & $47 \pm 4$ & 26 \\
Separated & $45 \pm 0$ & 3 \\
Group total & $47 \pm 5$ & 138 \\
\hline
\end{tabular}

\section{Age of Menopause by Current Age of Women}

The mean age at menopause was higher among the currently older women which shows that the mean age at menopause is in decreasing trend as shown in Table 5. 


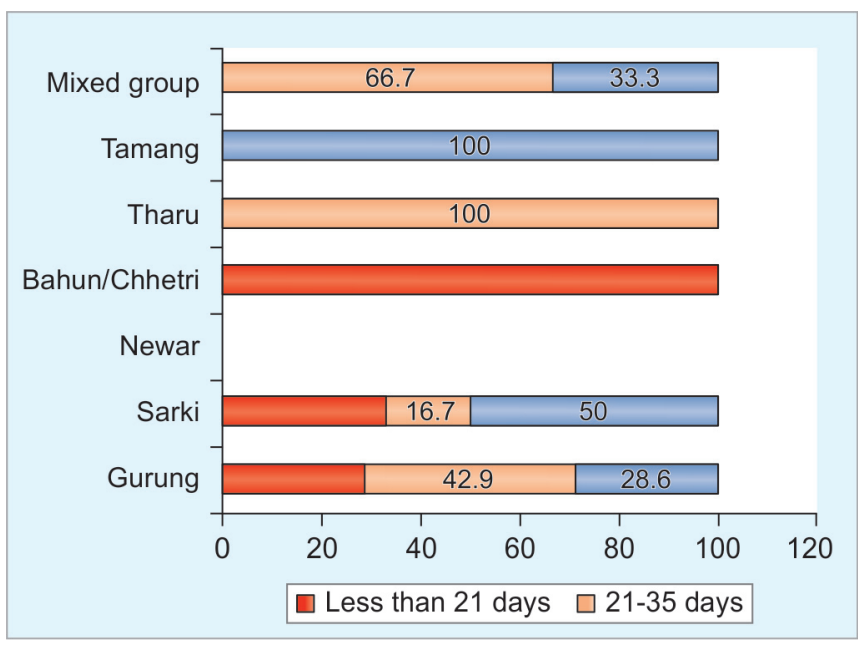

Graph 2: Current menstrual cycle (length) of perimenopausal women $(n=19)$

\section{Age of Menopause by Marital Status}

The mean age at menopause was highest among the unmarried women. However, there were a small number of unmarried women $(n=5)$ (Table 6).

\section{Length of Current Menstrual Cycle of Perimenopausal Women}

Graph 2 shows that $100 \%$ Brahmin/Chhetri women of perimenopausal had the menstrual cycle of less than 21 days while $100 \%$ Tharu had the menstrual cycle of 21 to 35 days. Women in other ethnic groups did not have uniform menstrual cycles within the groups itself.

\section{Length of Recent Menstrual Cycle of Postmenopausal Women}

Among 119 postmenopausal women, Sarki, Gurung and Tharu women had relatively more regular menstrual cycles before attaining menopause compared to Bahun/Chhetri and Tharu women. The proportion of different time periods of recent menstrual cycles before menopause is given in Graph 3.

\section{Bleeding Pattern during Perimenopausal Period}

One hundred percent Tharu women had heavy bleeding while 100\% Bahun/Chhetri and Tamang had normal bleeding during the peri-menopausal period. Women in other ethnic groups did not have uniform menstrual cycles within the groups itself (Graph 4).

\section{Amount of Bleeding in the Menstrual Cycle (Just before Menopause) among Currently Menopausal Women}

Nonspecific pattern was seen in the amount of bleeding in the most recent menstrual cycles among the currently menopausal women. However, Gurung, Bahun/Chhetri and

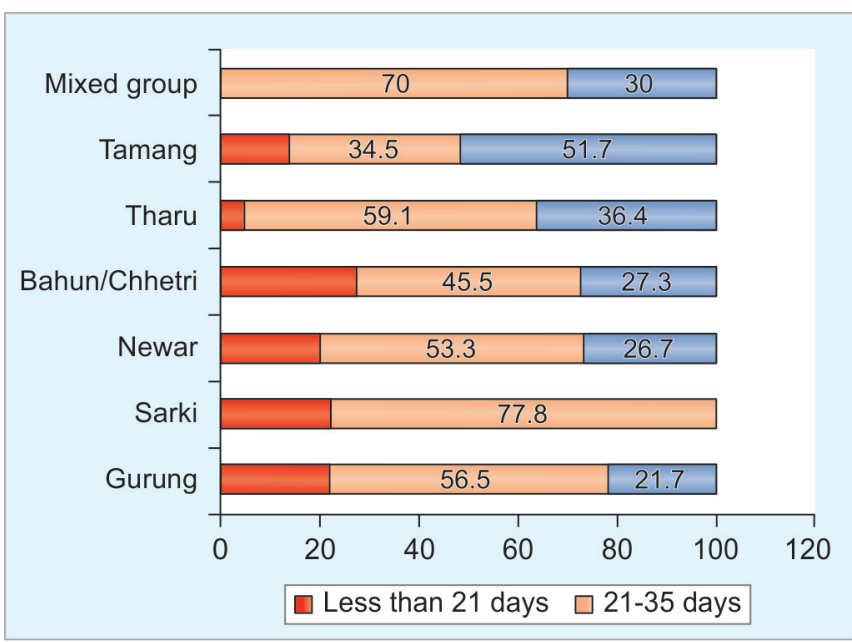

Graph 3: Recent previous menstrual cycle (days) of postmenopausal women $(n=19)$

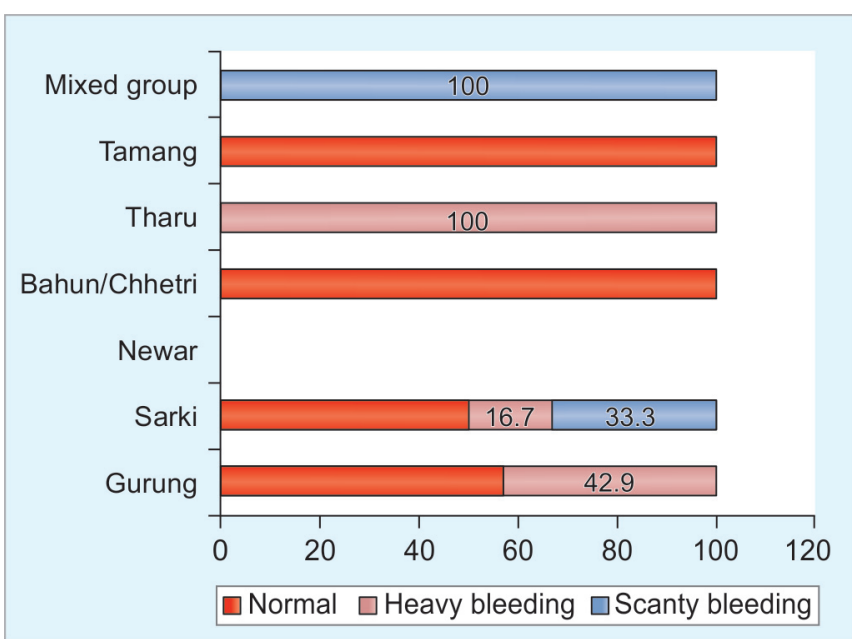

Graph 4: Amount of bleeding during perimenopausal period $(n=19)$

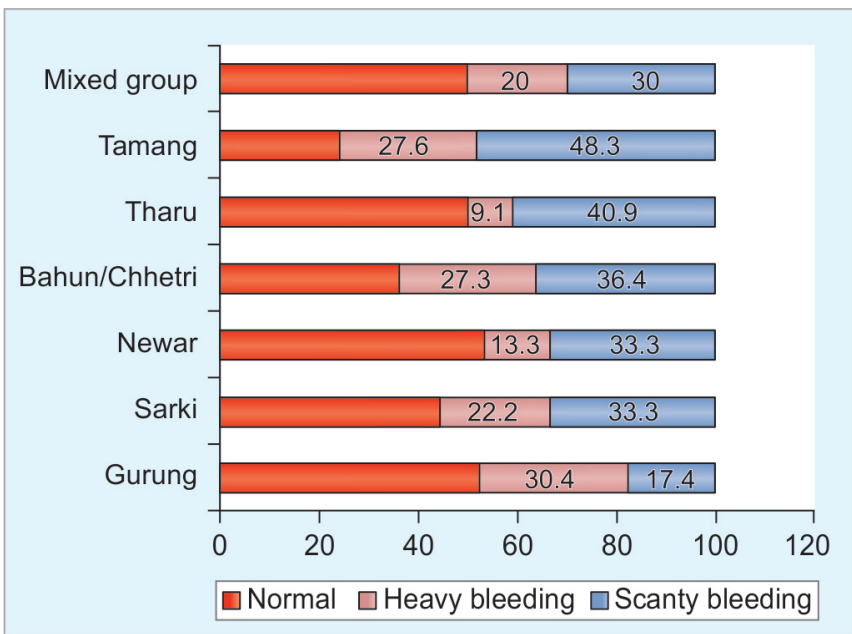

Graph 5: Amount of bleeding in the previous (most recent) cycle of currently postmenopausal women $(n=19)$

Tamang women had heavier bleedings compared to other ethnic groups. Scanty bleeding was seen in Tamang and Tharu women (48.3 and $40.9 \%$ respectively) as shown in Graph 5. 
Relation of Ethnicity and Menopausal Symptoms in Nepal

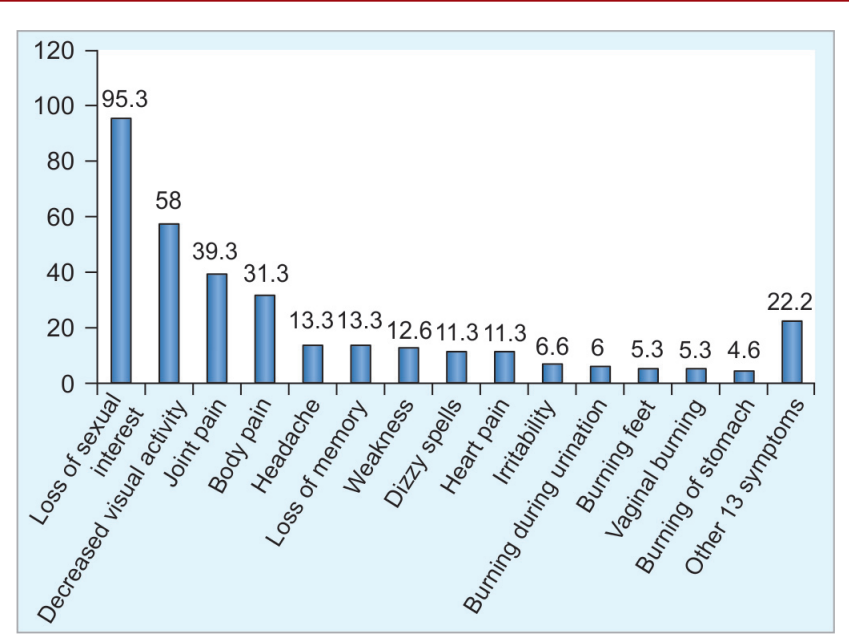

Graph 6: Percentage of menopausal symptoms in women identified by women themselves $(n=150)$

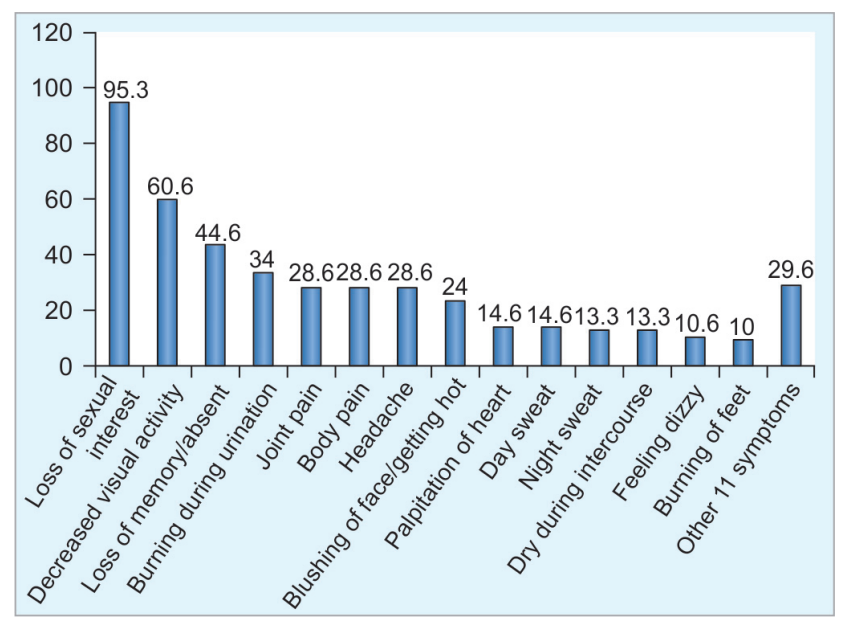

Graph 7: Menopausal symptoms experienced by other women during menopause

\section{Knowledge about Menopause}

Most of the women were aware about menopause but did not have detailed knowledge in terms of when menopause occurs and its symptoms. Knowledge about menopause was obtained from mothers, sisters, relatives, friends and neighbors.

\section{Menopausal Symptoms}

Common symptoms identified by the women were loss of sexual interest (95.3\%), decreased visual activity (58\%), joint pain (39.3\%), body pain (31.3\%) and so on. Out of 31 symptoms identified by women in various parts of the world, Nepalese women related to 27 symptoms (Graph 6).

\section{Menopausal Symptoms identified by Other Women (Global)}

Other women could identify a total of 25 symptoms of which the commonly reported symptoms were loss of sexual interest $(95.3 \%)$, decreased visual activity (60.6\%), loss of memory (44.6\%) and so on. The details on the identified symptoms are shown in Graph 7.
Table 7: BMI in perimenopausal women

\begin{tabular}{lll}
\hline Ethnicity & Mean $\pm S D$ & $N$ \\
\hline Gurung & $21 \pm 3.13$ & 7 \\
Sarki & $19.4 \pm 1.56$ & 6 \\
Newar & 0 & 0 \\
Bahun/Chhetri & $16.6 \pm 0$ & 1 \\
Tharu & $18.1 \pm 0$ & 1 \\
Tamang & $19.7 \pm 0$ & 1 \\
Mixed group & $20.3 \pm 0.78$ & 3 \\
Group total & $20 \pm 2.36$ & 19 \\
\hline
\end{tabular}

Table 8: BMI in postmenopausal women

\begin{tabular}{lll}
\hline Ethnicity & Mean $\pm S D$ & $N$ \\
\hline Gurung & $24.9 \pm 5.83$ & 23 \\
Sarki & $20.4 \pm 2.73$ & 9 \\
Newar & $18.1 \pm 3.72$ & 15 \\
Bahun/Chhetri & $18.3 \pm 4.65$ & 11 \\
Tharu & $19.4 \pm 4.82$ & 22 \\
Tamang & $21.2 \pm 3.43$ & 29 \\
Mixed group & $21.6 \pm 2.8$ & 10 \\
Group total & $21 \pm 4.8$ & 119 \\
\hline
\end{tabular}

\section{Body Mass Index (BMI)}

\section{Mean BMI in Perimenopausal Women}

Mean BMI was 20 in 19 perimenopausal women with the highest (21) being in Gurung women and the lowest (16.6) in Bahun/Chhetri women (Table 7).

\section{Mean BMI in Postmenopausal Women}

The mean BMI in postmenopausal women was 21 with the highest (24.9) being in Gurung women and lowest in Newar (18.1), Bahun/Chhetri (18.3) and Tharu (19.4) respectively (Table 8).

\section{Clinical Examination}

A total of 138 women underwent clinical examination including pap smear. Pap smear was normal in all 138 women. No other abnormalities were found among 19 perimenopausal women, however among the postmenopausal women one-third of Tharu had atrophic labia and one-third of Tamang women had leukoderma. Among 138 women examined $50 \%$ had cervical and vaginal-related problems like polyp, cervicitis and some had dry senile vaginitis.

\section{DISCUSSION}

The study reported in this paper attempts to determine the average age of menopause of Nepalese women and to find out the symptoms and complaints of Nepalese women among the different ethnic groups.

Among the respondents (75\% married, $18.8 \%$ widowed, $3.6 \%$ unmarried and $2.2 \%$ separated), the highest mean age of menarche was observed among Gurung, Bahun/Chhetri and Tamang communities as 16 years and lowest was 
observed in Tharu community as 13 years. The mean age of menarche was 15 years among all ethnic groups. According to a study conducted among school going girls of Western Nepal (Pokhara) determining the factors influencing age at menarche, the age at menarche was found to be $12.69 \pm 0.95$ years. The finding of the study shows slight variation as compared to this study. ${ }^{1}$ The slight variation can be attributed to the nature of the respondents including age at interview.

Among the respondents, $86.2 \%$ were in postmenopausal period and $13.8 \%$ were in perimenopausal period. The highest mean age of menopause was observed in Gurung community as 50 years while the least was observed in Bahun/Chhetri community as 44 years. The mean age of menopause was 47 years among all ethnic groups.

According to a study conducted in Palpa and Rupandehi districts of Nepal which found out the average age at menopause and identified the factors affecting the timing of menopause, the median age at menopause estimated by the life table technique was 47 years for the data consisting both completed as well as censored cases and 46 years for the data consisting only completed cases. ${ }^{2}$ This study showed that age at menopause was found similar for females belonging to Brahmin (46.4 years) and Chhetri (46.5 years) caste category. This also validates categorization of Bahun and Chhetri in one category in the present study paper. While the mean age at menopause of all women in both these studies remained nearly the same, mean age at menarche for Bahun/Chhetri community showed a noticeable decrease. Also according to a study conducted in two VDCs of Rupandehi district of Nepal, the range of age at menopause was found to be 38 to 56 years with the mean age of menopause as 46.81 years. ${ }^{3}$ A study conducted at Manipur, India, found the mean age at menopause among Nepali women living in Manipur as $47.44 \pm 0.38$ years. ${ }^{4}$

All the Brahmin/Chhetri women in perimenopausal period had the current menstrual cycle of less than 21 days while all the Tharu women of perimenstrual period had the current menstrual cycle of 21 to 35 days and all the Tamang women of perimenstrual period had the current menstrual cycle of more than 35 days. Women in other ethnic groups didn't have uniform menstrual cycles within the groups.

Among 119 postmenopausal women, more than 50\% of women of Gurung, Sarki, Newar and Tharu communities had menstrual cycle of 21 to 35 days while more than $50 \%$ of women in Tamang community had menstrual cycle of more than 35 days.

Among women of postmenopausal period, $50 \%$ or more had normal bleeding in Gurung, Newar and Tharu community while more than $30 \%$ women of all communities reported scanty bleeding except Tamangs (48.3\%). Heavy bleeding was reported by women of all the communities
(27.6\% Tamang, 9.1\% Tharu, 27.3\% Bahun/Chhetri, 13.3\% Newar, 22.2\% Sarki and 30.4\% Gurung).

The most commonly reported menopausal symptoms identified by women themselves were loss of sexual interest (95.3\%), decreased visual activity (58\%), joint pain (39.3\%), body pain $(31.3 \%)$, headache $(13.3 \%)$, loss of memory $(13.3 \%)$, weakness $(12.6 \%)$, dizzy spells $(11.3 \%)$, heart pain $(11.3 \%)$, irritability $(6.6 \%)$, burning during urination $(6 \%)$, burning feet $(5.3 \%)$, vaginal burning $(5.3 \%)$, burning of stomach (4.6\%). Almost all the women from all groups mentioned loss of sexual activity followed by decrease visual activity. Many except Gurung and Tamang identified headache as one of menopausal symptoms. The findings are in line with the findings of another study conducted in the USA titled 'ethnic differences in symptoms experienced during the menopausal transition'. According to the study, the most frequently reported symptoms experienced during menopausal transition across ethnic groups included 'allergy symptoms' (64\%), 'changes in vision' (61\%), 'feeling hot or cold' (61\%), 'forgetfulness' (61\%), 'sleep difficulty' $(54 \%)$ and 'stiff and sore joints' (52\%). ${ }^{5}$ Out of 31 symptoms identified by women in various parts of the world, Nepalese women related to 25 symptoms.

According to the study conducted in two VDCs of Rupandehi district of Nepal, general health problems as reported by respondents were gastritis $(38.3 \%)$, headache $(33.3 \%)$, eye problems (32\%), sleep disturbance $(30.7 \%)$ and musculoskeletal problems $(27.3 \%)$ followed by hypertension (19\%), diabetes (17.7\%). Menopausal problems as reported by respondents were dizzy spell (44.78\%), hot flushes $(23.88 \%)$, painful period $(19.40 \%)$ were more common in the age group 40 to 44 and palpitation $(53.64 \%)$, history of fracture $(44.90 \%)$, cold hand and feet $(10.20 \%)$ were more common in the age group 50 to 54 . Psychological problems were found most common in the age group 60 and above. ${ }^{3}$

In our study, it was seen that the Gurung women had attained the menarche later than the other women had menopause at a later age. This group of women had higher BMI compared to the rest although studies show the relation between BMI and menarche and menopause to be inversely proportionate. ${ }^{6,7}$ This could be explained by less number of Gurung women in our study group. BMI in late menopausal women shifted upward compared to that in early menopausal women. In premenopausal women, the main hormone is estradiol while in the postmenopausal, the main hormone is estrone. Following the cessation of hormonal production in the ovaries, they are produced exclusively from suprarenal androstenedione and aromatized to estrone in the process of peripheral extraglandular conversion. This transformation takes place mainly within fatty tissue which explains the greater adiposity in postmenopausal women. 


\section{ACKNOWLEDGMENTS}

The authors would like to thank Prof Kanti Giri and team for allowing us to use secondary data analysis from the original study (Menopausal Symptoms in Nepal by Prof Giri et al, July 2001). We would also like to thank all the women who participated in the study. We would like to thank Raj Kumar Subedi, MPH and Shakun Sharma, for helping with the data analysis and organizing the manuscript.

The authors do not have any conflict of interest and views shared are totally of the authors involved.

Menopausal Society of Nepal (MESON) was established in October 2012, and further information can be obtained from the website www.nesog.org.np

\section{REFERENCES}

1. Sunuwar L, Saha CG, Anupa KC, Upadhyay Dhungel K. Age at menarche of subpopulation of Nepalese girls. Nepal Med Coll J 2010 Sep;12(3):183-186.

2. Aryal TR. Age at menarche and its relation to ages at marriage. First-birth and menopause among rural nepalese females. Nepal Journal of Science and Technology 2011;12:276-285.

3. Acharya D, Gautam S, Neupane N, Kaphle HP, Singh JK. Health problems of women above forty years of age in Rupandehi district of Nepal. Int J Health Sci Res 2013;3(3):29-36.
4. Singh SJ. Ethnic variation in fertility patterns among four communities of Manipur. J Hum Ecol 2006;20(1):1-9.

5. Eun-Ok IM. Ethnic differences in menopausal symptoms experienced during the menopausal transition. Health Care for Women International 2009;30(4):339-355.

6. Skrzypczak M, Szwed A, Pawlińska-Chmara R, Skrzypulec V. Assessment of the BMI, WHR and W/Ht in pre- and postmenopausal women. Anthropological Review 2007;70: 3-13.

7. Akahoshi M, Soda M, Nakashima E, Tominaga T, Ichimaru S, Seto S, Yano K. The effects of body mass index on age at menopause. Int J Obes Relat Metab Disord 2002 Jul;26(7): 961-968.

\section{ABOUT THE AUTHORS}

\section{Swaraj Rajbhandari (Corresponding Author)}

Senior Consultant, Department of Obstetrics and Gynecology International MNCH Advisor, Free Lance Consultant, 643/43, Sneh Niwas, Thapathali, Kathmandu, Nepal, e-mail: swarajp07@yahoo.com

\section{A Amatya}

Associate Professor, Department of Community Medicine and Public Health, Institute of Medicine, Kathmandu, Nepal

\section{Kanti Giri}

Professor and Ex-Head, Department of Obstetrics and Gynecology Institute of Medicine, Kathmandu, Nepal 